\title{
Study on the water temperature of a bubble bath Shanghe $\mathrm{Chi}^{1, \mathrm{a}}$ \\ ${ }^{1}$ North China Electric Power University , Baoding 071003, China; \\ aletitiacsh@163.com
}

Keywords: Heat balance equation, Thermal conductivity, Heat exchange formula

\begin{abstract}
First,we analyze the effects of the bubble and human action on the model.Finally, we discuss the change of water temperature and plan when room temperatures changes. We take the water as surface layer and inner layer.There is static air storing in bubble.According to formula of thermal resistance of air layer, we can get thermal resistance of air layer.After adding bubble additive, fluctuation range of surface water temperature and hot water flow rate is reduced.And the average value is higher than before.
\end{abstract}

\section{Introduction}

Is there a bathtub in your home? Is the bathtub warm? Saving?

We believe that everyone has had a hot bath. After a hard day, it is a way to relax and enjoy. But the tub in the water with time gradually cool. How to ensure that in the process of the bath water to keep the constant temperature has been a problem. Want to enjoy a simple hot bath at home? Now, follow me, and I will show you how to enjoy a hot bath economically!

Different from previous methods of practical survey, we adopt some mathematical method to build an system for water temperature.In order to increase the bath comfort,people often use bubble additive in the bath. The surface of the water are covered with thick bubbles,greatly reducing heat dissipation.It has a good heat preservation effect.The calculated result is 0.0454 .

Friends who use this program, please enjoy life in the economy, practice conservation in life.Let's refuel together to design a more perfect solution.

\section{The Model}

If the person used a bubble bath additive while initially filling the bathtub to assist in cleaning,Heat dissipation of surface water will be affected. ${ }^{[1]}$

Table 1 Model parameters

\begin{tabular}{l|l}
\hline Parameter & Meaning \\
\hline$\lambda, \lambda_{c}$ & $\begin{array}{l}\text { Thermal conductivity,Radiation coefficient of air layer } \\
\text { The thickness, Conduction heat } \\
d, \theta\end{array}$ \\
$C^{\prime}, C_{i}$ & $\begin{array}{l}\text { The thickness of air layer,Temperature factor of air layer } \\
\text { Radiation coefficient of air layer,Radiation coefficient of air layer inner } \\
\text { surface material }\end{array}$
\end{tabular}




\begin{tabular}{l|l}
$C_{w}, C_{0}$ & $\begin{array}{l}\text { Radiation coefficient of air layer outer surface material, Radiation } \\
\text { coefficient of absolute black body } \\
\text { Thermal resistance of air layer }\end{array}$ \\
$P$ & Heat dissipated power \\
$\eta$ & Coverage area of bubble \\
$Q_{c}, Q_{e}$ & Toverage rate \\
\hline
\end{tabular}

Floating on the surface of the water,bubble has many small holes.There is part of the air stored in it.The air is changed from the original dynamic air into the static air.According to the data, the static air is equivalent to a thermal insulation material.According to the formula of thermal conductivity of air ${ }^{[2]}$, its thermal conductivity is

$\lambda=\frac{Q^{*} a}{A^{*} t\left(T_{2}-T_{1}\right)}$

According to the formula of thermal resistance of air layer ${ }^{[3]}$, Its thermal resistance of air layer is

$$
\begin{aligned}
& R=\frac{d}{\lambda+\lambda_{c}} \\
& \lambda_{c}=C^{\prime \prime} \times d \times \theta
\end{aligned}
$$

$\frac{1}{C^{\prime}}=\frac{1}{C_{i}}+\frac{1}{C_{w}}+\frac{1}{C_{0}}$

According to the relationship between heat dissipated power and thermal resistance of air layer $\frac{\Delta T}{R}=P$

So we can obtain the heat dissipated from bubble to air is

$$
d Q_{b}=P^{*} S * d t
$$

Because the bubble can not completely cover the entire surface area, so we define the bubble coverage rate is $\eta$.Then we can get the add of evaporation heat of surface water and the convection heat dissipation.

$d Q_{w}=(1-\eta)\left(d Q_{e}+d Q_{c}\right)$ 
According to the basic model, in the same way, we can obtain the relationship between surface water temperature and time and the relationship between flow rate of hot water and time.

\section{Numerical Computation}

According to the model,we can obtain the relationship between temperature of surface water and

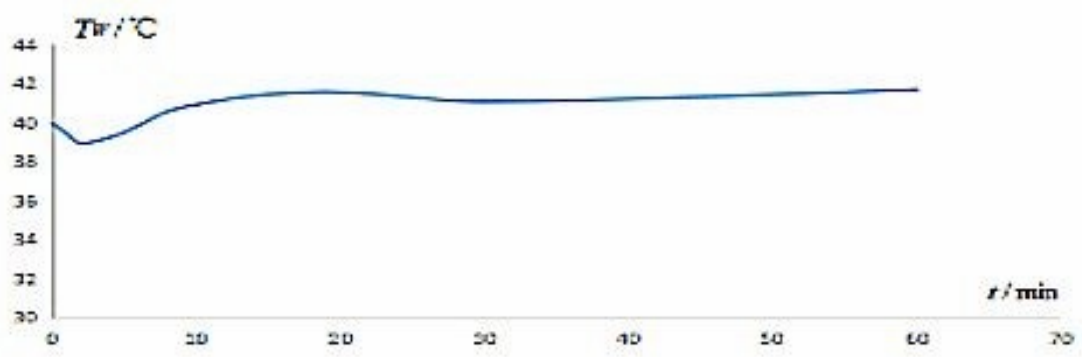

a

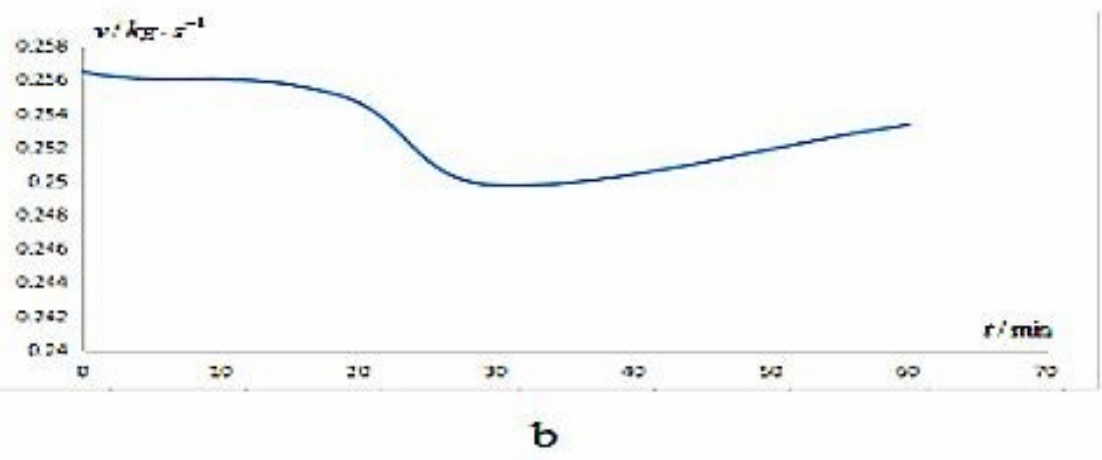

time like the Figure1.

Fig.1 Water temperature and velocity with bubble

\section{Sensitivity}

We discussed the changes of surface water temperature and hot water flow rate in the four seasons of a year. According to the life experience and information, we will set the spring room temperature to 20 degrees, the summer is 30 degrees, the autumn is 25 degrees, the winter is 15 degrees. According to the room temperature and the basic model, we can get the corresponding surface water temperature change with time. Spring is shown as Figure2(a),Summer is shown as Figure2(b),Autumn is shown as Figure2(c),Winter is shown as Figure2(d). 


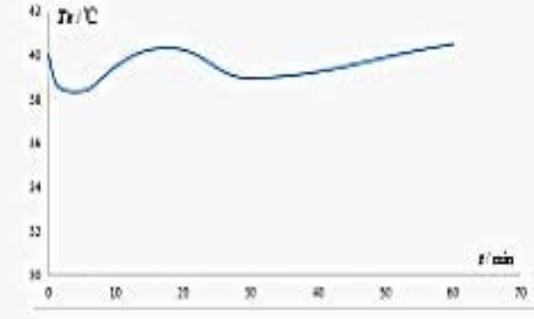

a

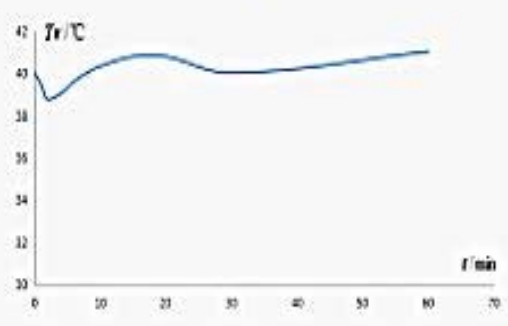

C

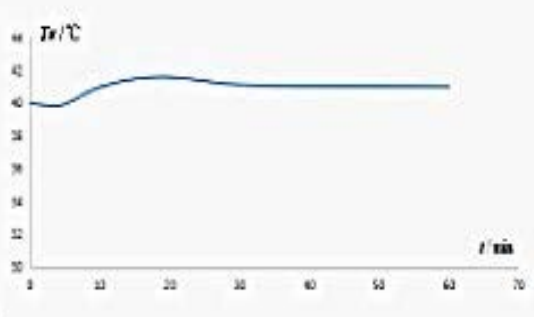

b

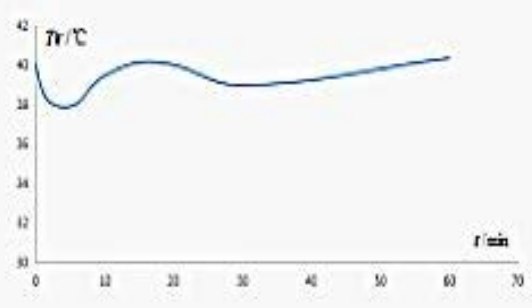

d

Figure2.Water temperature in different room temperature

According to the figure, we can see clearly that with the room temperature rising, fluctuations in the surface water temperature decreases gradually.And the overall temperature increases. This proves the reduction of heat dissipation to air convection and evaporative in surface water after room temperature rise.So the conclusion of numerical analysis is confirmed.

\section{Summary}

After adding the bubble additive, we can see that before the surface water temperature fluctuation amplitude is smaller.And the temperature is higher.Bubbles on the water surface played a role in heat preservation. It mainly affects the surface water evaporation heat and convection heat. After the use of bubble agent, the flow rate also has a corresponding reduction.

\section{References}

[1] Weijian Tan. Discussion on the influence of air in building materials on the thermal properties of materials.

[2] Anonymous . Calculation and measurement method of air layer thermal resistance. conference paper,2004

[3] Xiumu Fang,Yongcheng Jiang,Jianli Zhang. Construction technology [environmental testing Xiuyan. Beijing: Chinese architectural industry press].2002 